\title{
Mirko Tobias Schäfer on Entrepreneurial Research
}

KEYWORDs: entrepreneurial research; datafied society; data analysis; administrative research; data ethics

In this interview, we talk to Mirko Tobias Schäfer, associate professor at Utrecht University and principle investigator at the Utrecht Data School, based at the same institution. As the author of Bastard Culture: How User Participation Transforms Cultural Production (20II), Mirko has made an influential contribution to scholarship on online participation, debunking early, overly optimistic claims on the topic. ${ }^{\mathrm{I}}$ In $20 \mathrm{I} 3$, with Thomas Boeschoten, he initiated the Utrecht Data School (UDS), an educational platform where students acquire data analysis skills and carry out applied research projects in small groups, under the supervision of affiliated staff members. It was this experience, among others, that led to the subsequent publication, with Karin van Es, of the edited volume The Datafied Society: Studying Culture through Data (20I7). ${ }^{2}$

In what follows, Mirko talks about UDS's approach to studying datafication, which is centred on the idea of working directly with practitioners in order to produce research with 'impact', benefiting both academic research and various players in society. We also discuss the historical antecedents of this approach (most notably, as performed by Paul Lazarsfeld and his colleagues), as well as the critique this sort of initiatives has met with over time and Mirko's reaction to it.

- Eef Masson and Karin van Es

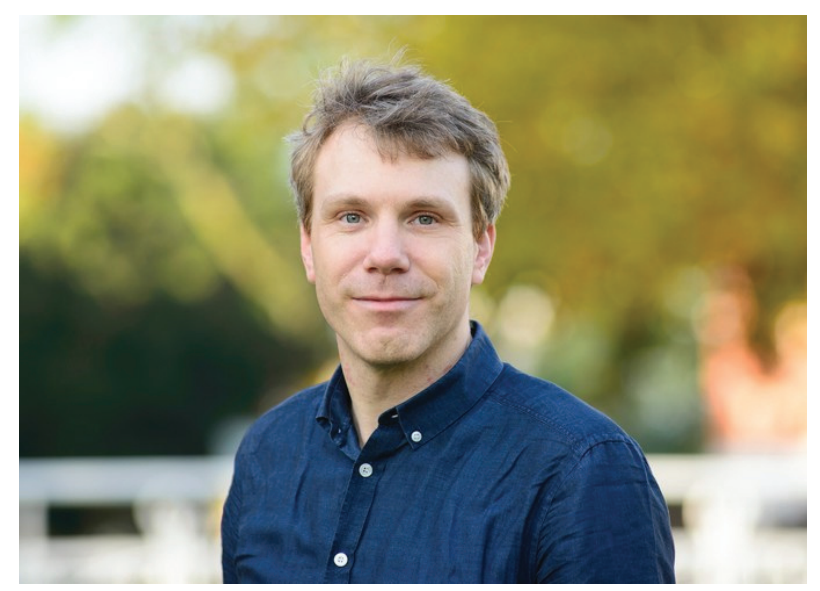

Mirko Tobias Schäfer. Photo: Maarten Kip. 
$E M / K v E$ : Can you say a few words first about the Utrecht Data School, an initiative at Utrecht University's Media and Culture Studies department to involve students in data analysis, as commissioned by external parties? What is UDS's purpose, and how does it work?

MTS: The Utrecht Data School is a platform for teaching data analysis and digital methods, and simultaneously, exploring practices and processes of datafication. Datafication concerns the systematic translation of everyday activities and social interaction into tabulated information, that can be employed for further data analysis. ${ }^{3}$ The sort of data we might think of here include, but are not limited to, user interaction data from websites and social media platforms, data from bank transactions and payment processes, data from public transport and traffic monitoring, data generated (and captured) as users access apps and services on mobile devices, and so on. The metaphor 'big data' - not necessarily a useful one - highlights that they constitute a vastly increasing resource, employed for analysis and in order to generate actionable intelligence; for instance, for innovating business processes and services, for improving public and corporate management, for disseminating media content and distributing goods and services, or for predicting all kinds of events.

UDS, founded in 2013 , provides a practicum for students from various disciplines in cooperation with societal partners: ministries, municipalities, companies and NGOs. In working with such partners, students apply and expand their newly obtained knowledge in data analysis and digital methods. Working on real-life projects, they experience on the ground how datafication manifests in organisations and companies, and are directly confronted with the issues arising from this profound transformation. At the same time, they have the opportunity to get acquainted with potential employers.

The objectives of the projects we conduct, as well as the methods, the quality of the data, and the issues addressed, vary widely. To name just a few: for the City of Gouda, our students have analysed environmental factors such as escape routes, architectural elements and plantation, but also social cohesion, looking for correlations with instances of residential burglary. For the mobility provider Radiuz, they have developed prototypes of dashboards for representing transportation data. For the Dutch Journalism Fund, they have investigated the impact of social media on local news.

$E M / K v E$ : In the past, you have used the phrase 'entrepreneurial research' to refer to what you do in the context of UDS. Can you explain what you mean by this, and discuss its key features?

MTS: Being quite unsuccessful in securing grants from the national and European funding bodies, we decided at some point to turn to external partners, such as public management organisations, companies and NGOs, asking them to commission research projects that would help fund our activities. As this idea caught on, UDS began to teach digital methods and perform critical inquiry of data issues, while at the same time providing a data analysis service to such institutions.

While our initial goal was merely to get a data school started, it ultimately transpired that the most valuable aspect of this set-up was actually the mutual exchange of knowledge between students, staff and external organisations. Teaching at UDS takes place in the very domain 
where our research interests - in datafication and its impact on democracy - manifest, and where new data practices change organisations, transform societal institutions, disrupt traditional relations between participants and stakeholders, and create both opportunities and threats to our society. Entering this domain as 'data experts' allowed us to immerse ourselves in these processes, as they take shape. Moreover, we realised that as researchers, we were not restricted to the role of observers, but could actually participate in the development of data practices - and this way, help shape the datafied society.

Working side by side with practitioners and policy makers provided rich and intimate insights into organisations and institutions. In other words, we used our 'commercial' activities as means for actually conducting research. This is the reason why I sometimes use the phrase 'entrepreneurial research': we offer services, that in turn provide us with privileged access to organisations. This way, we both gain insight into the particular ways in which our partners deal with datafication and change because of it, and have the opportunity to participate in tackling their challenges and in addressing any emergent issues.

It is important, in this context, to make the distinction between what I term 'entrepreneurial research' and 'academic entrepreneurship' - a practice condoned by many academic departments, especially outside the humanities. Academic entrepreneurship puts research findings to commercial gain; entrepreneurial research, in contrast, uses the activities of commercial companies (but in our case, also non-profits) to conduct research. As entrepreneurial scholars, we develop services and products that enable us to immerse ourselves more deeply into the domain of our research interests. Contact with partners in the field thus provides access to rich empirical data and case studies, that can in turn help us conceptualise the datafied society.

$E M / K v E$ : Can you give an example of a 'product' of such entrepreneurial research?

MTS: For example, UDS developed a Data Ethics Decision Aid that can be used to help an organisation understand its own data projects better while at the same time allowing us to learn more about the organisation and how it uses data. The decision aid (DEDA for short) is conceived of as a dialogical process to assess the ethical implications of data projects. It was developed in close cooperation with the City of Utrecht and its data analysts, with the objective of crafting a means for structurally reviewing a data project in its ethical dimensions.

Our DEDA process brings together the various people that are involved in a data project: data analysts, project managers, privacy officers, domain experts and policy makers. In answering questions concerning algorithms, data sources, access and social impact, anonymization, bias, responsibilities, and so forth, they become aware of potential ethical issues, and can decide how to tackle them. Moreover, documenting this dialogical process is one way of (beginning to) account for one's data practice. For the researchers involved, observing a DEDA process provides insight into an organisation's operational capacities concerning its data practices, into its sensibility towards issues in responsible data practice, and more broadly, into how data practices affect and change the organisation.

Aside from having developed the DEDA process and materials, UDS also offers DEDA workshops to external parties. Once again, these allow our researchers to learn more about 
organisations' current or planned data projects, about how they tackle ethical issues, and about how their organisations change in light of their data practices.

$E M / K v E$ : Arguably, your version of entrepreneurial research to some extent resembles Paul Lazarsfeld's administrative research, conducted at Columbia University in the I940s. Could you elaborate on this comparison?

MTS: Actually, we prefer to reference the work Lazarsfeld did earlier, in the I930s, along with his colleagues in Vienna. When the little town of Marienthal was struck by sudden mass unemployment as the local textile factory closed, Marie Jahoda, Paul Lazarsfeld and Hans Zeisel used the opportunity to study the social impact of unemployment.4 Instead of merely observing the residents in Marienthal, they developed a number of novel methods to capture rich data from these families' everyday lives. Providing instructional classes on housekeeping and mending clothes, and organising recreational activities, clothes drives and medical consultation hours to support the local population struggling with unemployment and poverty, the researchers not only gained trust, but also access to information. In a way, they successfully deployed charitable activities for capturing data. In some respects, this is similar to our approach, where we 'double up' on our services and products in order to immerse ourselves more deeply into our research domain, and in order to gain more insights. But thanks to the financial injection by our 'clients', we can also fund our research activities.

In his seminal article "Remarks on Administrative and Critical Communications Research", Lazarsfeld notes that administrative research 'is carried through in the service of some kind of administrative agency of public or private character.'5 He acknowledges that it is oftentimes subject to objections from two sides: from the external partners who had hoped to get more out of the research they paid for, and from scholars who find the research focus too narrow, arguing that it neglects the socio-political context of media production and reception. ${ }^{6}$

Much like Lazarsfeld's administrative research, our approach is quite descriptive in noting who is using which data practices, who has introduced them and to which end, which are the operational capacities of an organisation concerning data practices, and how they are being developed and utilised further. But subsequently, we use those insights to engage in a broader, critical examination of the issues raised by datafication, in order to understand the emergence of algorithmic governance and the transformation of citizenship and democracy. We strongly believe that our focus on creating impact and valorising research for application and policy development also leaves space for critical agency. For instance, with the help of our DEDA, we actively promote responsible data practices and we push municipal and state employees to critically review their data projects in terms of their ethical implications. We also hope that in the long term, the aid will provide opportunities for accountability, as its documentation affords public scrutiny of municipal data projects.

The debate between Lazarsfeld and his Frankfurt School colleagues Horkheimer and Adorno is still present in the reluctance of scholars from media and culture studies to engage in applied research, or even to cooperate actively with societal sectors.7 While some find that engaging in applied research stifles their theoretical reflection, we value the empirical evidence that it allows us to gather, the immediate impact our research efforts make, and the relevance it adds to humanities 
research. The computational turn, and the use of novel methods and skills within the humanities, allows us to leave the position of (mere) critical commentators - who primarily lecture to their own students - and to engage directly with various societal stakeholders. ${ }^{8}$

$E M / K v E$ : Arguably, Lazarsfeld failed in cross-fertilising administrative theory with critical theory. At UDS, how do you balance out the empirical demands of applied research and critical theory?

MTS: Here, it is worth referencing the conclusion Ruth and Elihu Katz draw in their review of administrative and critical research: 'the critical continues to rub off on the rest of us.' '9 However, I do acknowledge the difficulty of oscillating between applied research and critical inquiry. In part, this difficulty is due to the awkward role of today's universities, which promote openly societal cooperation and the valorisation of research findings (and even entrepreneurial activities) as well as to stress the importance of immediate societal impact, but are also challenged in providing the required infrastructure, and often stuck in dated models of managing staff and organising research.

Project administration is modelled largely around the four-year to six-year funding schemes of the large research funding agencies. For us, this presents trivial, but also very real problems. For instance, it means that our administrative SAP account always indicates a negative result; the reason is that even though we earn the money before we spend it (as we should), the software calculates four years into the future, deciding that our project has produced a negative result. In addition, we sometimes also have to invest in research and business opportunities (as we did with the DEDA, which was only possible because other research projects generated enough revenue to make such an investment). This is difficult to explain to administrators, who are used to thinking that one does not start spending money until the funding one applied for has been received. Finally, there is the issue of hiring people. As the university is reluctant to hire staff on permanent contracts, we lose key people, because their temporary contracts won't be renewed indefinitely.

However, the biggest challenge for the UDS staff is to carry out two jobs at once: doing research with and for external partners, and valorising the results in fundamental academic research. While the data school focuses on teaching and applied research, our Datafied Society research platform connects scholars from various disciplines. These two platforms are highly entwined, and often, students and researchers are involved in the projects of both. Oftentimes, an applied research project also leads to academic research, and student teams contribute to such research by carrying out data capturing and contributing to data analysis. But at times, we do have to let go of promising research opportunities, simply because we have to move on to the next (paid) project. At the end of the day, we have to earn the money to keep UDS and the Datafied Society research platform running.

If universities would be more open to entrepreneurial research and provide appropriate infrastructure and funding as well as incentives to engage in this kind of endeavours, our model could be very effective. It would connect teaching to research, provide opportunities for additional funding, and facilitate significant impact and effective social engagement. I am confident that entrepreneurial research does not only help researchers to emancipate from the research 
funding lottery and the at times monolithic power structures in academia, but also to more effectively access institutions, organisations and communities for their research purposes. As such, these forms of administrative research, as Lazarsfeld called them, can be of great value also for critical research.

$E M / K v E$ : In the past, you have argued that humanities scholars need to adapt to the datafied society, in terms of skills and competencies. Can you explain how you see this?

MTS: As Karin and I have argued in our book The Datafied Society: Studying Culture through Data (20I7), the computational turn provides humanities scholars with unprecedented access to data resources: digitised corpora, previously inaccessible resources, and data from web platforms, electronic consumer devices or tools built for data capturing. The emerging datafied society confronts us with a wide range of uncomfortable questions concerning the transformation of culture, the public sphere, governance and civic participation - to name just a few. Technology and how societies regulate it will largely determine how we will live in the twenty-first century. Digitisation and datafication increasingly affect all areas of everyday life, but also education, political organisation and cultural heritage. It affects how we interact with each other as family, friends, employees or citizens in a larger society. As such, the so-called 'big data' are not merely an issue for data scientists, computer scientists and engineers, but also for humanities scholars, whose expertise and critical inquiry is very much needed in shaping the datafied society.

As humanities' scholars, we are required to obtain new skills, to develop what Bernhard Rieder and Theo Röhle call digital Bildung: an understanding of algorithmic thinking, basic statistics and programming, and an impulse to question the institutional aspects of data practices as much as to develop an informed response to the newly emerging positivism. ${ }^{\text {I0 }}$ But most importantly, we have to leave the comfort zone of our classrooms and lecture halls. Humanities scholars are needed where algorithms turn into black boxes, where data practices determine individual livelihoods, where privacy is breached and accountability is undermined for corporate or political gain. There are great role models and initiatives blazing the trail: Danah Boyd, who founded the Data and Society think tank; Kate Crawford, who directs the AI Research Now Institute; the Public Data Lab; the Berlin-based Algorithm Watch; the Data Justice Lab at Cardiff University; William Uricchio and the team at MIT's Open Documentary Lab; Ethan Zuckerman and the team at the MIT Centre for Civic Media; Ronald Deibert and the team at Citizen Lab; and many, many more. They show how scholars can situate their research at the cross-section of academia and societal sectors. Their research informs public debates and provides much-needed information for opinion making and developing points of view. It should be noted, then, that valuable research also takes place outside academia, and that the university has no monopoly on either critical or administrative research.

\section{Notes}

I. Mirko Tobias Schäfer, Bastard Culture! How User Participation Transforms Cultural Production (Amsterdam: Amsterdam University Press, 20II).

2. Mirko Tobias Schäfer and Karin van Es, ed., The Datafied Society: Studying Culture through Data (Amsterdam: Amsterdam University Press, 20I7). 
3. Viktor Mayer-Schönberger and Kenneth Cukier, Big Data: A Revolution that Will Transform How We Live, Work, and Think (London: John Murray, 2013).

4. Marie Jahoda, Paul F. Lazarsfeld, and Hans Zeisel, Marienthal: The Sociography of an Unemployed Community [original title: The Arbeitslosen von Marienthal] (I93I; New Brunswick: Transaction, I97I).

5. Paul Felix Lazarsfeld, "Remarks on Administrative and Critical Communications Research," Studies in Philosophy and Social Science 9, no. I (I94I): p. 2-I6, specifically 8.

6. Lazarsfeld, "Remarks".

7. Elihu Katz and Ruth Katz, "Revisiting the Origin of the Administrative versus the Critical Research Debate," Journal of Information Policy 6 (2016): 4-I2.

8. See also Karin van Es and Mirko Tobias Schäfer, "Introduction: Brave New World," in The Datafied Society, ed. Schäfer and Van Es, I3-22.

9. Katz and Katz, "Revisiting the Origin," II.

Io. Bernhard Rieder and Theo Röhle, "Digital Methods: From Challenges to Bildung", in The Datafied Society, ed. Schäfer and Van Es, Io9-I24.

\section{Biography}

Mirko Tobias Schäfer is an associate professor of New Media and Digital Culture at Utrecht University and principal investigator at Utrecht Data School. His research interests revolve around the socio-political impact of (media) technology. His publications cover user participation, datafication, and communication in social media. Mirko is co-editor and co-author of the volume Digital Material: Tracing New Media in Everyday Life and Technology (2009) and author of the book Bastard Culture! How User Participation Transforms Cultural Production (20II). Most recently, he edited, with Karin van Es, the volume The Datafied Society: Studying Culture through Data (20I7). 